\title{
GENE FREQUENCIES IN THE DOMESTIC CATS OF YORK: EVIDENCE OF SELECTION
}

\author{
JUDITH A. METCALFE and JOHN R. G. TURNER \\ Department of Biology, University of York, England
}

Received 21.v.70

\section{INTRODUCTION}

RECENT work on the population genetics of the domestic cat has shown that not only do the frequencies of the various coat colours differ between Europe and the Far East, but also these frequencies differ between Europe and North America; as the North American population was presumably derived from that of Europe about two centuries ago, this indicates rapid evolution (Searle, 1964; Todd, 1966). The present survey gives an additional estimate of frequencies in the cat population of England, the country from which one assumes a large proportion of North American cats, as of North American people, are derived; and makes a comparison between the frequencies of a relatively small town and the large London conurbation, in the same way that certain small French towns have been compared with Paris (Dreux, 1967a, b, c, 1968c). The data has also been used to discuss the problems of randomness of mating, randomness of sampling, and selection-natural or otherwise.

York is a comparatively small city, based on a medieval walled town, with a human population of about 108,600. It has a small amount of light industry, and is still used as an agricultural market centre. Air pollution from large industrial cities further west and from local domestic fires is fairly heavy. The city is much less urban in character than London, which lies 200 miles to the south.

The cats, scored at the R.S.P.G.A. home for animals in York, consisted of adults and kittens brought in by their owners, and stray animals brought in by R.S.P.C.A. inspectors and members of the public, both from York and from surrounding rural areas. We scored the following characters:

dominant white versus coloured $(W,+)$; Maltese dilution versus full colour $(d,+)$; agouti ticking versus non-agouti $(+, a)$; blotched tabby versus striped tabby $\left(t^{b},+\right)$; and the sex-linked character black versus orange $(+, O)$ of which the heterozygote is tortoiseshell.

Two other characters which are frequently used in cat population genetics, Abyssinian tabby (plus lined tabby) and chinchilla dilution, have not been used, as they were very infrequent and we were accordingly uncertain of our ability to score them correctly; for the present study Abyssinian and lined tabbies have been included with striped tabbies. There were no Siamese or Burmese dilutions. We also scored the amount of white spotting on the scale suggested by Dreux $(1968 a)$; for numerical calculations his category $\epsilon$ has been called 0.05 .

Visits were made to the R.S.P.C.A. home for animals twice a week in order to score newly arrived cats and kittens; over 80 per cent. of the continually changing population was scored over a period of 12 months. The 
complete phenotype of each animal was recorded on a punched card, the frequencies of particular characters being determined by sorting the cards.

\section{Results}

Table 1 shows the number of cats of each phenotype among adults, kittens, and kittens in litters. We have included all kittens in every litter as

TABle 1

Numbers of phenotypes of cats in Tork

Phenotype
Dominant white
Coloured

Maltese dilution

Full colour

Agouti

Non-agouti

Blotched tabby

Other tabby

Black

Tortoiseshell

Orange

\begin{tabular}{|c|c|c|c|}
\hline \multicolumn{2}{|c|}{ Adults } & \multicolumn{2}{|c|}{$\begin{array}{l}\text { Single } \\
\text { kittens }\end{array}$} \\
\hline$\sigma^{x}$ & 우 & 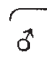 & 우 \\
\hline 3 & 5 & 0 & I \\
\hline 115 & 107 & 40 & 49 \\
\hline 7 & 16 & 4 & 0 \\
\hline 108 & 91 & 36 & 49 \\
\hline 28 & 32 & 15 & 20 \\
\hline 64 & 73 & 16 & 27 \\
\hline 29 & 19 & 14 & 13 \\
\hline 19 & 11 & 9 & 9 \\
\hline 92 & 68 & 31 & 39 \\
\hline- & 37 & - & 8 \\
\hline 22 & 2 & 10 & 2 \\
\hline
\end{tabular}

\begin{tabular}{rr}
\multicolumn{2}{c}{ Sibships } \\
o & \multicolumn{1}{c}{ o } \\
4 & 4 \\
179 & 196 \\
7 & 14 \\
172 & 182 \\
49 & 60 \\
86 & 125 \\
51 & 48 \\
39 & 24 \\
135 & 139 \\
- & 46 \\
44 & 11
\end{tabular}

these will be a random sample of the population, provided that the mothers and the mates of the mothers are themselves a random sample mated at random. The analysis of genotype frequencies at the sex-linked locus (see later) shows no significant departure from Hardy-Weinberg frequencies; thus the assumption appears to be justified. Differences in frequencies between males and females, and between adults, solitary kittens and kittens

TABLE 2

Gene frequencies in York and some other localities

\begin{tabular}{|c|c|c|c|c|c|c|}
\hline Locality & Reference & $W$ & $d$ & $a$ & $t^{b}$ & $O$ \\
\hline York & 一 & $0 \cdot 01$ & $0 \cdot 27$ & $0 \cdot 81$ & $0 \cdot 78$ & $0 \cdot 20 *$ \\
\hline S. England & Robinson and Silson (1970) & $0 \cdot 01$ & $0 \cdot 26$ & $0 \cdot 80$ & $0 \cdot 84$ & $0 \cdot 19$ \\
\hline London & Searle (1949) & $<0.01$ & $0 \cdot 14$ & $0 \cdot 76$ & $0 \cdot 81$ & $0 \cdot 11$ \\
\hline Mayenne & Dreux $(1968 c)$ & 0.01 & $0 \cdot 29$ & $0 \cdot 64$ & $0 \cdot 61$ & $0 \cdot 15$ \\
\hline Paris & Dreux $(1967 c)$ & $0 \cdot 02$ & 0.33 & $0 \cdot 71$ & $0 \cdot 78$ & $0 \cdot 06$ \\
\hline Boston & Todd (1964) & $0 \cdot 02$ & $0 \cdot 43$ & $0 \cdot 64$ & $0 \cdot 44$ & $0 \cdot 19$ \\
\hline
\end{tabular}

* Arithmetic mean of frequencies in males and females $(0 \cdot 23$ and $0 \cdot 17)$.

in litters appear (with one possible exception discussed later) to be nothing more than random; animals of each sex and all ages have been pooled to obtain the gene frequencies given in table 2 ; the frequency of the sex-linked orange allele has been calculated separately for males and for females. The frequencies of the autosomal genes have been calculated on the assumption of Hardy-Weinberg proportions.

The histogram in fig. 1 shows the distribution of white spotting in the 
sample; the mean amount of spotting was $0.2 \mathrm{l}$, with a variance of 0.05 (standard deviation 0.22 ), there being no significant difference between adult cats and kittens.

\section{Comparison With OTHer cirties}

Table 2 shows the frequencies of the various genes found in York, London, the South of England, Paris, Mayenne, and Boston (U.S.A.). The

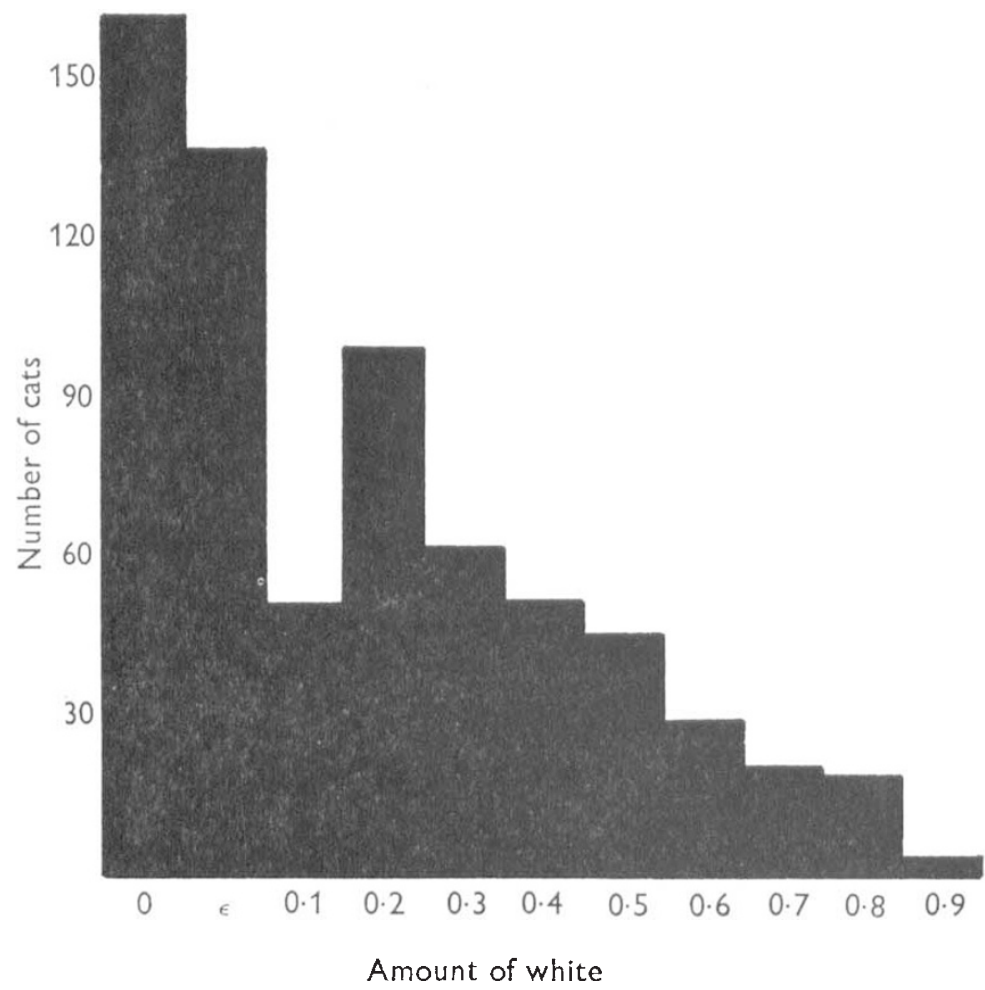

FIG. 1.-Frequency distribution of white spotting in cats (including all kittens) in York.

frequency of dominant white is very low in all cities, and seems to show little significant variation. The frequency of Maltese dilution in York is markedly higher than in London, but lies within the range of frequencies normally found in Europe, and is considerably lower than in Boston. Non-agouti is at a higher frequency than in any of the other cities, but not very much higher than in London. Blotched tabby occurs at about the same frequency in York as in London and Paris, and at a much higher frequency than in Boston. Orange is at about the same frequency in York as in Boston and is decidedly higher than in the other three European towns. It has been suggested (Dreux, 1967c, 1968c) that extreme urban environments do not favour the orange allele. Thus its frequency is lower in Paris than in Mayenne; our results for York tend to confirm this as orange is at a very much lower frequency in the intense urban environment of London than in York. The frequencies of all alleles in York are very close indeed to those found in 
southern England; it is not possible to tell whether the difference from London is one of space or time.

Dreux (1967b) noted that in rural France white spotting was commoner than in Paris (Paris 53 per cent., Mayenne 70 per cent.); York shows also an increase in white spotting (76 per cent.) compared with London (61 per cent.) (all percentages including $\epsilon$ ).

\section{Selection}

Our data shows that, at least at the black-orange locus, the York population does not depart from binomial proportions; in other words the cats are

TABLE 3

Correspondence of frequencies at the sex-linked locus to Hardy-Weinberg ratios (females only), in York

$\begin{array}{lccc} & \text { Black } & \text { Tortoiseshell } & \text { Orange } \\ \text { Observed } & 246 & 91 & 15 \\ \text { Expected } & 241 \cdot 4 & 100 \cdot 2 & 10 \cdot 4 \\ \text { Gene frequency } & 0 \cdot 828 & - & 0 \cdot 172 \\ & \chi_{(1)}^{2}=2 \cdot 97,0 \cdot 10>\mathrm{P}>0 \cdot 05 . & \end{array}$

mating roughly at random (table 3 ). The expected and observed frequencies of black, tortoiseshell and orange cats among the females agree closely and $\chi_{(1)}^{2}$ is not significant.

According to one's general views on the genetics of populations, one might suppose either that coat colour variation in cats is a polymorphism maintained by some kind of selection-either human aesthetic selection or natural selection-or that the genes are entirely neutral in their selective effects, the variations in frequency from place to place resulting from random processes. The sex-linked black-orange locus gives us an opportunity for making a tentative choice between the hypotheses. At a sex-linked locus subject to random mating but to no selection, the proportions of genotypes in the population are $p, q$ in males and $p^{2}, 2 p q, q^{2}$ in females, where the gene frequencies are $p, q$. However, these proportions are not produced by a single round of random mating but are approached asymptotically; consequently if the population is subject to natural selection, not even the zygotes produced from random mating will occur in these proportions. This is one of the properties of equilibrium under selection of a sex-linked locus $(\mathrm{Li}, 1967)$. If mating is random, the proportions of the genotypes in the females will be $p^{2}, 2 p q, q^{2}$, but the gene frequencies in males and females will be different. Therefore it is possible to detect the effects of selection on a sex-linked locus, by looking for a difference in the gene frequencies between males and females.

At the black-orange locus in the cat we can count all the genes present in the population, apart from those masked by the dominant white gene. Black and tabby cats, including the dilutes, manifest one + allele in males and two + alleles in females, orange cats manifest one $O$ allele in males and two $O$ alleles in females; and tortoiseshell cats manifest one + and one $O$ allele.

Table 4 shows the number of $O$ and + alleles for all samples published up to the preparation of this paper, including York. An appropriate significance test for the association of gene-frequency and sex is the analysis of $\chi^{2}$ 
proposed by Woolf (1955) (for a concise summary see Race and Sanger, 1962) as modified by Edwards (1965). Association between colour and sex is measured by the cross-ratio of the numbers (black gene in males $\times$ orange gene in total sample)/(orange gene in males $\times$ black gene in total sample), tabulated as $x$ in table 4 . If there is no association between colour and sex, this ratio will be unity. Each sample is given the weight (table 4)

$$
w=\left(1 / n_{+}+1 / n_{0}-1 / \mathcal{N}_{+}-1 / \mathcal{N}_{0}\right)^{-1}
$$

where the $n$ are the numbers of genes in the males and the $\mathcal{N}$ are the numbers of genes in the total sample.

TABLE 4

Analysis of the incidence of black and orange alleles in males and females

\begin{tabular}{|c|c|c|c|c|c|c|c|}
\hline \multirow[b]{3}{*}{ Locality } & \multicolumn{4}{|c|}{ Number of genes } & \multirow[b]{3}{*}{$x$} & \multirow[b]{3}{*}{$w$} & \multirow[b]{3}{*}{ Reference } \\
\hline & \multicolumn{2}{|c|}{ Males } & \multicolumn{2}{|c|}{ Females } & & & \\
\hline & + & $O$ & + & $O$ & & & \\
\hline York & 258 & 76 & 583 & 121 & 0.795 & $92 \cdot 86$ & This paper \\
\hline London & 311 & 42 & 608 & 68 & 0.886 & $59 \cdot 36$ & Searle (1949) \\
\hline Paris & 451 & 34 & 1271 & 75 & 0.840 & $45 \cdot 72$ & Dreux $(1967 c)$ \\
\hline Chamonix & 17 & 5 & 33 & 5 & 0.680 & $7 \cdot 20$ & Dreux $(1968 b)$ \\
\hline Marseille & 122 & 13 & 257 & 15 & 0.693 & $21 \cdot 38$ & Dreux (1969) \\
\hline Mayenne & 211 & 34 & 603 & 107 & $1 \cdot 075$ & $38 \cdot 71$ & Dreux $(1968 c)$ \\
\hline Venezia & 48 & 8 & 132 & 10 & $0 \cdot 600$ & $11 \cdot 80$ & Searle (1966) \\
\hline Den Haag & 309 & 82 & 340 & 92 & $1 \cdot 010$ & $122 \cdot 80$ & Dreux and Legel (1969) \\
\hline New York & 97 & 18 & 186 & 30 & 0.914 & $24 \cdot 10$ & Todd (1966) \\
\hline Rochester & 34 & 5 & 171 & 45 & $1 \cdot 659$ & $4 \cdot 89$ & Searle (1964) \\
\hline Columbus & 51 & 24 & 221 & 87 & 0.867 & $20 \cdot 58$ & Tinney and Griesemer (1968) \\
\hline Boston & 99 & 28 & 252 & 56 & $0 \cdot 846$ & $32 \cdot 19$ & Todd (1964) \\
\hline Chicago & 97 & 28 & 220 & 64 & $1 \cdot 005$ & $31 \cdot 25$ & Todd (1969) \\
\hline San Francisco & 39 & 20 & 70 & 32 & 0.930 & $21 \cdot 17$ & Searle (1964) \\
\hline Singapore & 74 & 38 & 181 & 79 & 0.893 & $36 \cdot 55$ & Searle (1959) \\
\hline Mishima & 71 & 43 & 212 & 142 & 1.079 & $35 \cdot 21$ & Komai (1952) \\
\hline Gotemba & 35 & 17 & 116 & 34 & 0.695 & $16 \cdot 35$ & Komai (1952) \\
\hline Brisbane & 108 & 18 & 240 & 40 & $1 \cdot 000$ & $22 \cdot 37$ & Moffatt (1968) \\
\hline Melbourne & 23 & 9 & 114 & 14 & 0.429 & $9 \cdot 63$ & Moffatt (1968) \\
\hline
\end{tabular}

The $\chi^{2}$ analysis is then

$$
\begin{aligned}
& \text { Total contingency }=(\Sigma w \ln x)^{2} / \Sigma w=8.35 \text { ( } 1 \text { d.f.) } \\
& \text { Total } x^{2}=\Sigma\left\{w(\ln x)^{2}\right\}=26.97 \text { (19 d.f.) } \\
& \text { Heterogeneity (by difference) }=18.62 \text { (18 d.f.) } \\
& \text { Weighted mean of } x=\text { antilog }(\Sigma w \ln x) / \Sigma w=0.89
\end{aligned}
$$

Thus there is no significant heterogeneity between samples $\left(\chi_{(18)}^{2}=18 \cdot 62\right.$; $0.5>\mathrm{P}>0.3$ ) (that is, all populations are consistent in this respect), b there is a significant heterogeneity within samples $\left(\chi_{(1)}^{2}=8.35 ; 0.01>P\right)$. Therefore it is likely that the gene frequencies do differ in males and females, with an excess of black in females and of orange in males.

There is a possible objection to this conclusion. As tabby-tortoiseshell cats sometimes have only small tufts of yellow hair, it is possible for them to be scored as tabby cats; mis-scoring of this type would result in an excess of black genes in females. We felt that we may sometimes have made such a mistake. Further, from the overall frequency of agouti and non-agouti 
phenotypes, about one-third of the tortoiseshells should have been tabbytortoiseshells; in fact, only 18 out of 91 tortoiseshells were tabby, suggesting that we may indeed have mis-scored in this way. Robinson and Silson (1970) suggest that their sample may be similarly mis-scored, and the fact that the York data do not differ significantly from those from other places, must mean that if this is the cause of the excess of black in females, the majority of other workers have made the same error. Therefore there are two ways of testing the hypothesis that the association of colour and sex shown by the combined data is due to mis-scoring of tabby tortoiseshell cats. If it is, then there should be a correlation between the strength of the association measured (by $\ln x$ ) and (i) the deficiency of tortoiseshells compared with the expected Hardy-Weinberg frequency, and (ii) the frequency of the $+^{a}$ gene, or agouti phenotype.

Fig. 2 shows that there is no such correlation, and therefore we are inclined to believe that there is a real difference in the gene frequencies between males and females. If so it must mean that some kind of selection is being exercised on the black-orange locus. This poses us a very interesting question: is the population really one in which black genes are in excess in females, with the cats brought to the animal shelter being a random sample; or are the animals which come to the shelter the ones which are less wanted by their owners, and are hence turned out of the house or brought for destruction? The first would mean that black was at an advantage in females, the second that orange was at an advantage. Either way the result indicates the action of selection, but it would be very interesting to know which way the selection is tending.

If the samples recorded are true random samples of the population, then we can estimate the relative fitness of the two male genotypes from the formula (cited by Li, 1967)

fitness of black/fitness of orange $=$ (black gene in males $\times$ orange gene in females)/(orange gene in males $\times$ black gene in females)

using either frequencies or numbers. It is easy enough to show that at equilibrium this formula applies to gene frequencies either in zygotes or adults. By the method of Woolf (1955), the weighted mean for this ratio in the world data (table 4 ) is $0.85 \pm 0.06$; black males are therefore on average only about 85 per cent. as fit as orange males, with 95 per cent. confidence limits of 97 per cent. and 73 per cent. Also it follows from the condition for stability in such a system $(\mathrm{Li}, 1967)$ that if tortoiseshell females have arbitrary fitness of 1.00 , the fitness of orange females is less than 0.93 and that of black females less than $1 \cdot 09$, if the equilibrium is stable and fitness is not frequency dependent.

Table 5 gives further evidence of such selection; the cats and single kittens are divided into stray cats and those which were brought to the shelter by their owners. In the adult males there is a significant deficiency of orange cats among the strays $\left(\chi_{(1)}^{2}=6.53,0.02>\mathrm{P}>0.01\right)$; the kittens do not show this, and if they are pooled with the adults the result is not significant $\left(\chi_{(1)}^{2}=3 \cdot 07,0 \cdot 10>\mathrm{P}>0 \cdot 05\right)$. Counting genes the females show a non-sigificant excess of the orange gene among the strays in both adults and kittens $\left(\chi_{(1)}^{2}=1 \cdot 81,0.2>P>0 \cdot 1\right)$. (Discrepancies between tables 1 and 5 result from unscored cats; sibships have not been analysed.) The difference in the frequency of orange females in adults and kittens (table l) is also worth 
noting. Other loci show no marked differences between strays and pets (Metcalfe and Turner, 1970).

Obviously no firm conclusion can be drawn from this result unless it can be confirmed in other cities, but the excess of the black gene in male

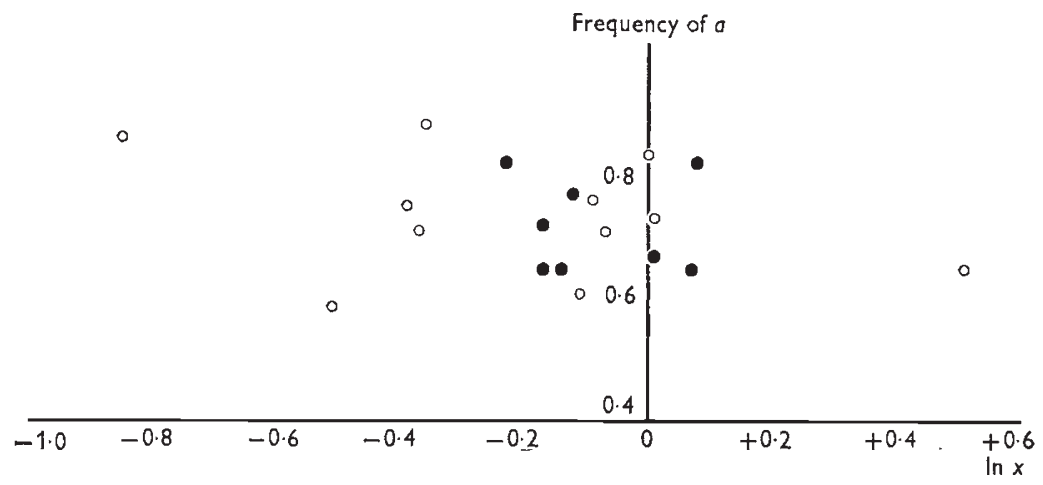

FIG. $2 a$

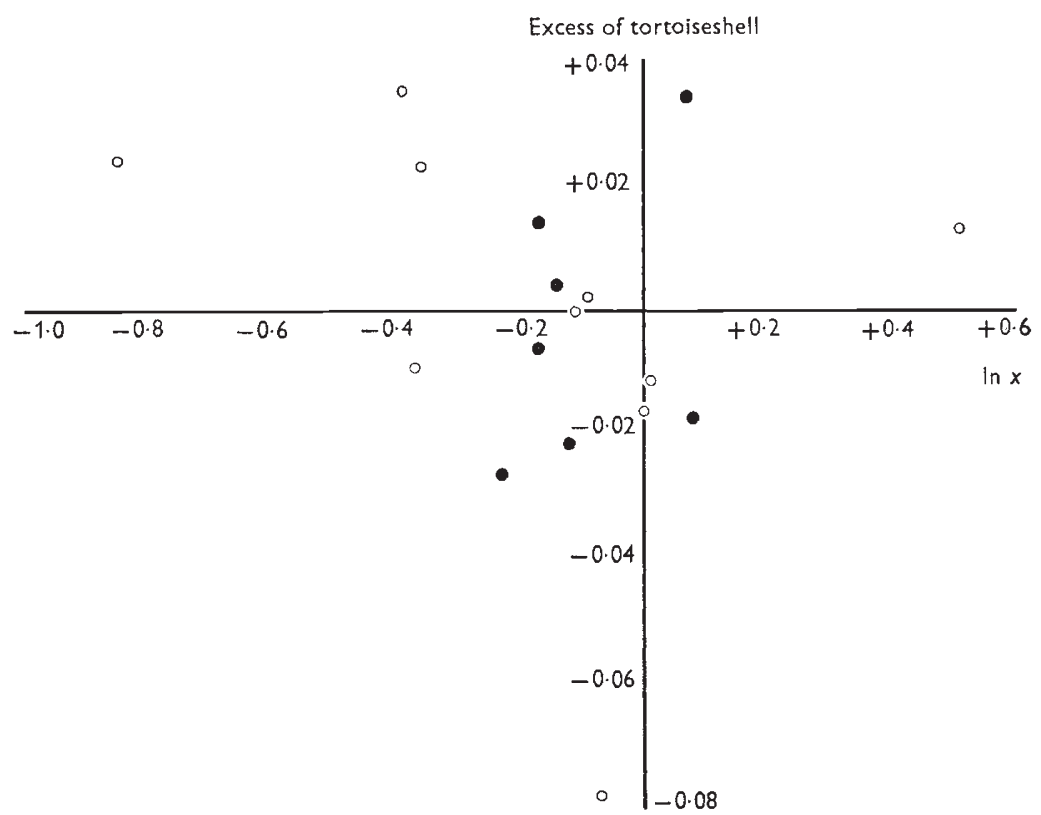

FIG. $2 b$

Fig. 2.-Relationship between $\ln x$ at the black-orange locus in the cat (data from all samples reported in the literature) and (a) the frequency of the non-agouti gene and (b) the excess of tortoiseshell females over expectation as a proportion of the total sample size. Large black spots indicate samples with more than 150 females (excluding white cats). One sample of 216 females (den Haag) is off the graph in fig. $b ; \ln x$ is +0.01 and the excess of tortoiseshell is $-0 \cdot 16$. Venezia is not plotted in fig. $b$, as the method of scoring the sample produced a bias towards tortoiseshell.

strays and the orange gene in female strays might indicate selection in the direction needed to produce the association of colour and sex already noted. It is not of course by any means certain that a pet cat, with its presumably 
higher risk of castration, is at a selective advantage to a stray, and the difference could indicate either human aesthetic selection in the retention of certain colours as pets, or natural selection in the stray population. We thus offer no firm conclusion, but note that all the data suggest that some kind of selection is occurring at this locus.

Robinson and Silson (1970) found an excess of orange cats in southern England, but as their sample was not scored for sex it is not possible to tell whether this results from the relations we have shown, or from non-randomness of mating, or from a disturbed sex-ratio.

TABLE 5

Phenotypes at the black-orange locus, classified according to the origin of the cat (York data)

\begin{tabular}{|c|c|c|c|c|c|c|c|c|}
\hline \multirow[b]{2}{*}{ Phenotype } & \multicolumn{2}{|c|}{ Male adult } & \multicolumn{2}{|c|}{ Female adult } & \multicolumn{2}{|c|}{ Male kitten } & \multicolumn{2}{|c|}{ Female kitten } \\
\hline & Stray & Owner & Stray & Owner & Stray & Owner & Stray & Owner \\
\hline Bla & 79 & 12 & 55 & 12 & 15 & 15 & 17 & 22 \\
\hline Tortoiseshell & - & - & 33 & 4 & - & - & 6 & 2 \\
\hline Orange & 14 & 8 & 0 & 1 & 6 & 4 & 1 & 1 \\
\hline
\end{tabular}

\section{Conglusions}

The gene frequencies of cats in York are obviously in close accord with those found in other European and North American cities (with certain interesting exceptions) and are almost identical with those in southern England, but it would be premature to speculate on any reasons for similarities or differences. It has been suggested (Dreux, 1967c) that the sexlinked allele black is favoured by urban environments, and a comparison between the frequencies in London and in York would seem to confirm that this is so; but obviously more paired comparisons of this kind must be made before the correlation can be regarded as significant.

In some ways domestic cats seem rather unsuitable for work on population genetics; although it seems virtually certain that the cats do mate more or less at random with regard to colour (tests on the frequencies of the phenotypes black, tortoiseshell and yellow in many cities including York confirm this), it is difficult to know to what extent the cats brought into animal shelters are a random sample of the cats in a city. Also it would be very difficult to unravel the role of natural selection, part of it presumably taking place in the very complicated and somewhat inaccessible environment of the urban cat, and of artificial selection by human preference, this taking place in circumstances probably accessible only by the methods of sociology. However, among animals it is very rare to find a colour polymorphism in which all the genotypes are distinguishable; as the cat does provide this, and as there is evidence from the accumulated data from a large number of cities and from analysis of the data for York that the genes at this sex-linked locus are subject to some kind of selection, the cat seems a worthwhile organism to study.

\section{Summary}

1. The gene frequencies for coat colour of cats have been estimated from the animals recorded at the animal shelter in York. 
2. The gene frequencies in York are similar to those in other cities in western Europe and in the north east United States: dominant white is infrequent as in all other cities; Maltese dilution is at a frequency similar to that of European cities rather than of the United States; non-agouti is at a very high frequency, a little higher than that in London; blotched tabby is at the high frequency characteristic of north-west Europe; and orange is at a higher frequency than in London, seeming to confirm the suggestion that this allele is not favoured in urban environments. Frequencies in York are almost identical with those in southern England.

3. The numbers of black, tortoiseshell and orange females (the sexlinked locus) indicate that the cats in York mate roughly at random with respect to colour, but the combined data for York and all other cities so far published show an overall significant excess of orange alleles in males and of black alleles in females. This suggests, according to standard theories of selection at sex-linked loci, that the locus in question is under some kind of selection, natural or artificial.

4. As many cities have been surveyed using shelters for unwanted animals, it is not clear in which direction selection is tending, but in York the frequencies of the black-orange locus seem to differ between stray and pet cats.

Acknowledgments.-We are very grateful to the Royal Society for the Prevention of Cruelty to Animals, and particularly to $\mathrm{Mr}$ and Mrs W. Stericker, without whose kind help this work would have been impossible; also to $\mathrm{Dr}$ L. M. Cook for his helpful critique of a draft, particularly of the statistical analysis, and to Dr A. G. Searle for his help in tracing some of the references; and to all those workers who have given us permission to quote their data circulated privately in Carnivore Genetics Newsletter, but otherwise unpublished.

\section{REFERENGES}

DREUX, PH. 1967a. Fréquence des gènes chez les chats d'un district rural français. Carn. Genet. Newesletter, 1, No. 2, 26-28.

DREUX, PH. 1967b. Génétique des populations de chats domestiques en Europe occidentale. Annales de Genetique, 10, 141-145.

DREUX, PH. 1967c. Gene frequencies in the cat population of Paris. 7. Hered., 58, 89-92. DREUX, PH. 1968a. Panachure chez le chat (II). Carn. Genet. Neresletter, 1, No. 4, 64-65.

DREux, PH. 1968b. Fréquence des gènes chez les chats de Chamonix (France, HauteSavoie). Carn. Genet. Newsletter, 1, No. 4, 62-63.

DREUX, PH. 1968c. Gene frequencies in the cat population of a French rural district. $\mathcal{F}$. Hered., 59, 37-39.

DREUX, PH. 1969. Fréquences des gènes chez les chats de Marseille. Carn. Genet. Newesletter, 1, No. $6,118-120$.

DREUX, PH. AND LEGEL, J. c. 1969. Premières données sur les chats de la Haye (den Haag). Carn. Genet. Newsletter No. 6, 122-124.

EDWARDS, J. H. 1965. The meaning of the associations between blood groups and disease. Ann. hum. Genet. (London), 29, 77-83.

комаI, т. 1952. Incidence of the genes for coat colours in Japanese cats. Annot. Zool. Fapon., 25, 209-211.

LI, c. c. 1967. Genetic equilibrium under selection. Biometrics, 23, 397-484.

METCALFE, J. A., AND TURNER, J. R. G. 1970. Frequency of genes in the domestic cat in York, England. Carn. Genet. Neresletter, 1, No. 9, 213-215.

mofFAтt, B. w. 1968. Cat gene frequencies in two Australian cities. F. Hered., 59, 209-211. RAGE, R. R., AND SANGer, R. 1962. Blood Groups in Man. Fourth edition. Blackwell, Oxford.

ROBINSON, R., AND SILSON, M. 1970. Mutant gene frequencies in cats of southern England. Theoret. gen. Genet., 39, 326-329. 
SEARLE, A. G. 1949. Gene frequencies in London's cats. 7. Genet., 49, 214-220.

SEARLE, A. G. 1959. A study of variation in Singapore cats. 7. Genet., 56, 111-127.

SEARLE, A. G. 1964. The gene-geography of cats. Journal of Cat Genetics, 1, 18-24.

SEARLE, A. G. 1966. Coat colour gene frequencies in Venetian cats. Carn. Genet. Neresletter No. 1, 6-7.

SEARLE, A. G. 1968. Cat gene-geography: the present picture. Carn. Genet. Neresletter No. $4,66-73$.

TINNEY, L. M., AND GRIESEMER, R. A. 1968. Gene frequencies in the cats of Columbus, Ohio, U.S.A., and a comparison of north east U.S. populations. Carn. Genet. Neresletter No. 5, 96-99.

TODD, N. B. 1964. Gene frequencies in Boston's cats. Heredity, 19, 47-51.

TODD, N. B. 1966. Gene frequencies in the cat population of New York City. 7. Hered., 57, 185-187.

TODD, N. B. 1969. Cat gene frequencies in Chicago and other populations of the United States. 7. Hered., 60, 273-277.

woolf, B. 1955. On estimating the relation between blood group and disease. Ann. hum. Genet. (London), 19, 251-253. 